\title{
Ir-Catalyzed Chemodivergent Allenylic Alkylation of Vinyl Azides: Highly Enantioselective Synthesis of $\alpha$-Allenylic Amides and Ketones
}

\author{
Aditya Chakrabarty and Santanu Mukherjee* \\ Department of Organic Chemistry, Indian Institute of Science, Bangalore - 560012, India
}

\begin{abstract}
Enantioselective allenylic alkylation reactions of unstabilized enolates have never been reported. We now present a unified fragment-coupling strategy for the first enantioselective synthesis of $\alpha$-allenylic amides and ketones through allenylic alkylation of vinyl azides. In these chemodivergent reactions, cooperatively catalyzed by $\operatorname{Ir}(\mathrm{I}) /$ (phosphoramidite,olefin) complex and Sc(OTf) ${ }_{3}$, vinyl azides act as the surrogate for both amide enolates and ketone enolates. The desiccant (molecular sieves) plays a crucial role in controlling the chemodivergency of this enantioconvergent and regioselective reaction: Under otherwise identical reaction conditions, the presence of the desiccant led to $\alpha$-allenylic amides while its absence resulted in $\alpha$-allenylic ketones from the same substrate combinations. Utilizing racemic allenylic alcohols as the alkylating agent, the overall process represents a dynamic kinetic asymmetric transformation (DyKAT), where both $\alpha$-allenylic amides and ketones are formed with the same absolute configuration generally with outstanding enantioselectivity. To the best of our knowledge, this is the first example of the use of vinyl azide as the ketone enolate surrogate in an enantioselective transformation.
\end{abstract}

\section{INTRODUCTION}

Building molecular complexity through fragment-coupling reactions has remained a sought-after strategy in organic synthesis. ${ }^{1}$ In this realm, perhaps few reactions can match the versatility displayed by transition-metal-catalyzed asymmetric allylic substitution (AAS). ${ }^{2}$ The past five decades have witnessed remarkable developments in this direction, especially under Pd and Ir-catalysis, and resulted in the coupling of innumerable nucleophilic fragments with allylic units. ${ }^{3,4}$

Therefore, it is perplexing that despite the rich synthetic expediency of the allene functionality, ${ }^{5}$ the structurally similar allenylic substitution reactions (Scheme 1A) are far less developed. Like AAS reactions, here also the initial studies were focused on Pd-catalysis, ${ }^{6}$ possibly due to the obvious mechanistic resemblance. A few enantioselective allenylic substitution reactions of selected nucleophiles were subsequently developed, leading to the generation of axial chirality, ${ }^{7}$ central chirality ${ }^{8}$ and even both. ${ }^{9}$

The entry of iridium into the stage of allenylic substitution is a relatively recent phenomenon and followed the discovery of the Ir-catalyzed AAS reactions. In 2004, Takeuchi et al. reported the allenylic alkylation of malonate diesters using an $\operatorname{Ir}(\mathrm{I}) /$ dppe complex. ${ }^{10}$ In analogy with the Pd-catalysis, the reaction was proposed to proceed through an $\eta^{3}$-butadineyl Ir(III) intermediate. Rather surprisingly, despite notable promise, this report remained in oblivion for more than a decade. In 2018, Carreira and co-workers resurrected this reaction using an $\operatorname{Ir}(\mathrm{I}) /$ (phosphoramidite,olefin) catalyst and developed the first enantioselective allenylic alkylation reaction under Ir-catalysis. ${ }^{11} \mathrm{~A}$ detailed investigation from the Carreira group revealed the mechanistic uniqueness of this Ir-catalyzed allenylic substitution reactions compared to both Pd-catalyzed allenylic substitution $^{6-9}$ as well as Ir-catalyzed allylic substitution. ${ }^{4}$ Contrary to the initially postulated $\eta^{3}$-butadineyl Ir(III) intermediate, ${ }^{10}$ these reactions were shown to proceed through an allenylic carbocation intermediate having an $\eta^{2}$-coordination of $\operatorname{Ir}(\mathrm{I})$ with the terminal double bond of allenes and do not involve any change in the formal oxidation state of iridium during the reaction (see Scheme 2). ${ }^{11}$

While further developments are imminent, only a handful of nucleophiles have been employed so far. ${ }^{12}$

We sensed an opportunity in developing unprecedented fragment-coupling reactions with the goal of introducing allenylic functionality. While considering possible unstabilized nucleophilic fragments, it came to our attention that there is no report on the synthesis of $\alpha$-allenylic amides, let alone an enantioselective variant (Scheme 1B). This is despite the prevalence of both amides and allenes in natural products and bioactive compounds. ${ }^{13} \mathrm{An}$ apparent cause of this glaring gap in synthetic toolbox is possibly the attenuated acidity of the amide $\alpha$-protons, ${ }^{14}$ which necessitates the use of a strong base for enolization. This shortcoming of amide $\alpha$-reactivity has previously been supplemented using amide enolate surrogates. ${ }^{15}$ Vinyl azide is one such surrogate, and the pioneering studies by Chiba and co-workers have demonstrated its synthetic potential. ${ }^{16}$

We envisioned an enantioselective allenylic alkylation reaction of vinyl azide for the synthesis of $\alpha$-allenylic amides (Scheme 1C). 
Scheme 1. Catalytic Asymmetric Allenylic Substitution Reactions in the Context of the Present Work

(A) Asymmetric allenylic substitution reactions
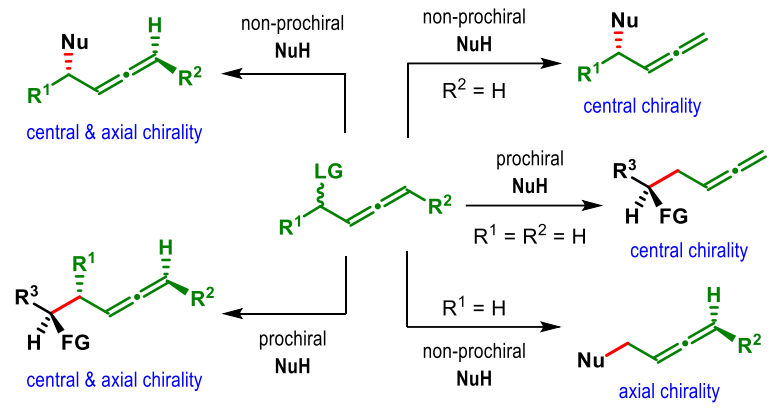

(B) Enantioselective $\alpha$-allenylic alkylation of carbonyls: state-of-the-art

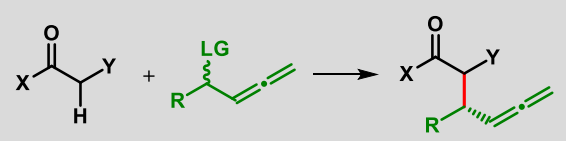

- Carbonyl nucleophiles:
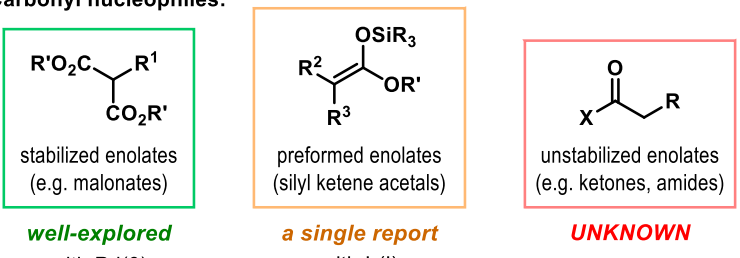

with $\operatorname{Pd}(0)$

with $\operatorname{Ir}(\mathrm{I})$

(C) This work: A unified fragment-coupling approach to $\alpha$-allenylic amides \& ketones

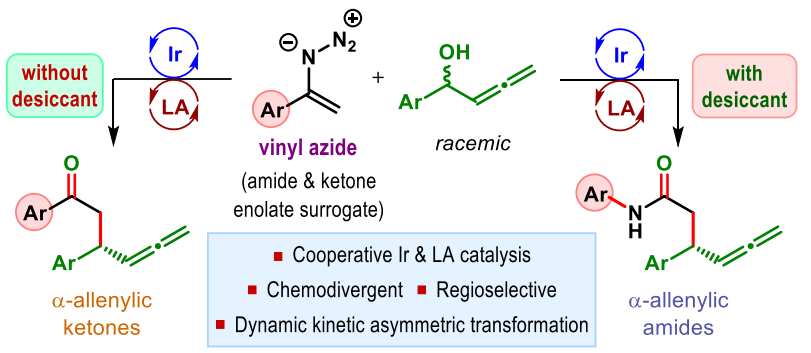

Our strategy is based on the cooperative $\operatorname{Ir}(\mathrm{I})$ and Lewis acid catalysis (Scheme 2). Allenylic alcohol (A), in the presence of a Lewis acid promoter, has been shown to react with $\operatorname{Ir}(\mathrm{I})$ to form an allenylic carbocation B having its terminal double bond coordinated with $\operatorname{Ir}(\mathrm{I})$ in an $\eta^{2}$-fashion. 12a,c We realized that $\mathbf{B}$ can be trapped by the nucleophilic vinyl azide $\mathbf{C}$ to generate iminodiazonium ion $\mathbf{D}$, possibly as an equilibrating mixture of $(E)$ - and $(Z)$-isomers. ${ }^{16 i}$ This $\mathrm{C}-\mathrm{C}$ bond forming step should be irreversible and enantiodetermining. Schmidt rearrangement of $(E)$-D involving an aryl migration would then result in the nitrilium ion $\mathbf{E}$. Addition of the hydroxide, released from the allenylic alcohol, to $\mathbf{E}$ followed by tautomerization would then furnish the desired $\alpha$-allenylic amide $\mathbf{F}$. Schmidt rearrangement of (Z)-D, on the other hand, would lead to preferential alkyl migration en route to $\alpha$-allenylic $N$-acyl methylamine $\mathbf{F}^{\prime}$. In yet another competing pathway, both $(E)$ - and $(Z)$-D could undergo hydrolysis either with the Lewis acid-bound hydroxide or with residual water present in the reaction medium to afford $\alpha$-allenylic ketone $\mathbf{G} .{ }^{16 \mathrm{i}}$
Scheme 2. Mechanistic Hypothesis of Asymmetric Allenylic Alkylation of Vinyl Azides under Cooperative Iridium and Lewis Acid Catalysis
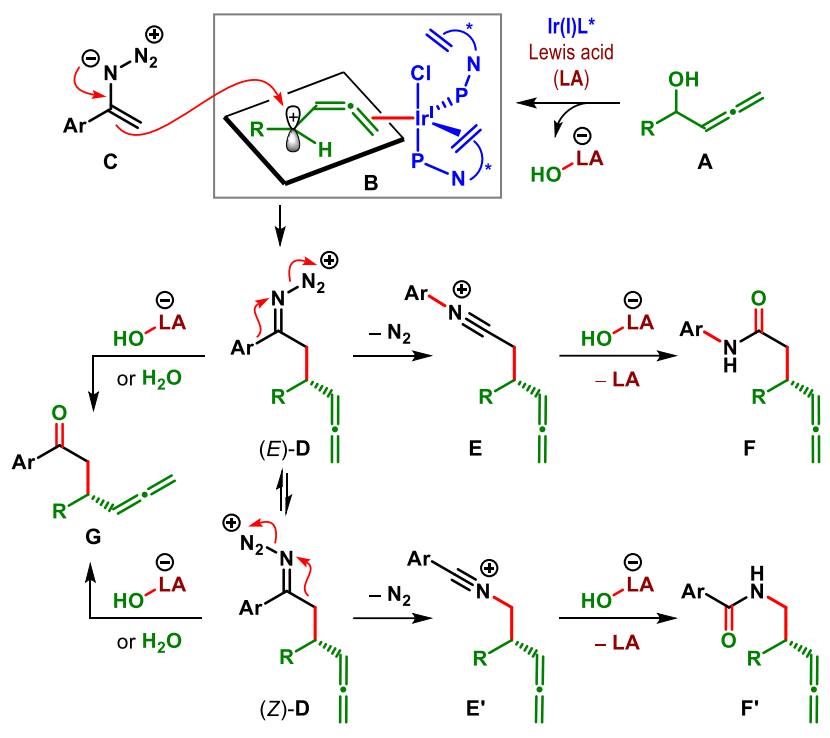

While these selectivity issues pose a potential hurdle to our strategy, taking a cue from our earlier study, ${ }^{15 a}$ we were confident in controlling the diastereoselectivity of iminodiazonium ion in favor of $(E)$-D using sterically and electronically tuned vinyl azides, and thereby eliminating the possibility of formation of $\mathbf{F}^{\prime}$. At the same time, we wondered about turning the chemoselectivity problem (Schmidt rearrangement vs. hydrolysis of $\mathbf{D}$ ) into our advantage and developing an enantioselective synthesis of $\alpha$-allenylic ketones ${ }^{17}$ from the same set of starting materials by harnessing the reactivities of either $(E)$-D or $\mathbf{E}$ with controlled hydroxide (or water) concentration.

Even though the use of vinyl azide as amide enolate surrogate in enantioselective reactions has recently been reported, ${ }^{15 a-b,}{ }^{16 a}$ its application as ketone enolate surrogate ${ }^{16 \mathrm{i}}$ is yet to be disclosed for an enantioselective transformation.

Scheme 3. Possible fragment-coupled products in the reaction of vinyl azides with allenylic alcohols

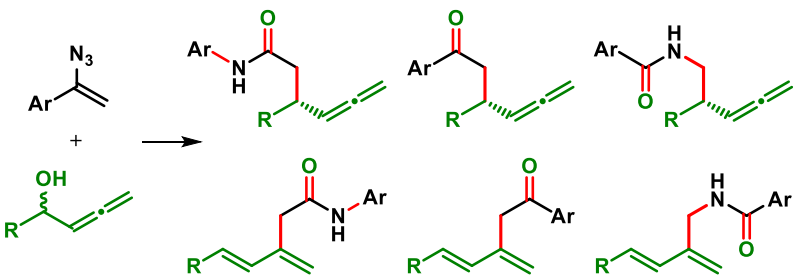

However, for such reactions to become useful, the competing fragment coupling pathways must be suppressed besides imposing chemo- and enantioselectivity. In addition to the selectivity problems discussed above (Scheme 2), transition metal catalyzed allenylic substitution reactions are known to be associated with the formation of 1,3-dienes depending on the nature of the nucleophiles. ${ }^{18}$ Consequently, in a reaction of vinyl azide with an allenylic electrophile, a 
total of six fragment-coupled products are possible (Scheme 3).

The seminal studies by the Carreira group offer sufficient evidence that the regioselectivity in favor of the allene over 1,3-diene could be achieved using the $\operatorname{Ir}(\mathrm{I}) /$ (phosphoramidite,olefin) complex as the catalyst. ${ }^{11}$ At the same time, hydroxide concentration can be kept at check with the help of a suitable desiccant ${ }^{15}$ a to navigate the reaction pathways either towards $\alpha$-allenylic amides or ketones.

We herein present the successful implementation of this strategy and report a unified enantioselective synthesis of $\alpha$-allenylic amides and ketones, through an efficient chemodivergent and regioselective allenylic alkylation of vinyl azides (Scheme 1C).

\section{RESULTS AND DISCUSSION}

Our initial task was to identify the optimum sets of reaction conditions for achieving the desired chemodivergency and regioselectivity besides enantioselectivity. We began our study focusing on the synthesis of $\alpha$-allenylic amides. It was clear at the outset that in order to achieve this goal, simply controlling the geometry of the initially formed iminodiazonium ion $\mathbf{D}$ will not be sufficient (Scheme 2). Its reactivity must also be guided toward Schmidt rearrangement over hydrolysis. Accordingly, 1-(o-methoxyphenyl) vinyl azide $1 \mathbf{a}$ (Table 1) was selected with the anticipation of the preferential generation of $(E)$-D because of the steric bulk of the aryl group. At the same time, the electron rich nature of the aryl ring should facilitate its migration over hydrolysis of the iminodiazonium ion.

The allenylic alkylation of 1a with either allenylic alcohol rac-2a or its carbonate $r a c-\mathbf{2} \mathbf{a}$ ' was, therefore, chosen as the model reaction for the synthesis of $\alpha$-allenylic amide $\mathbf{3 a a}$. No product formation was found to take place when the reaction between $1 \mathbf{a}$ and rac-2a' was carried out in THF at 50 ${ }^{\circ} \mathrm{C}$ in the presence of $6 \mathrm{~mol} \%$ of a catalyst derived from $[\operatorname{Ir}(\mathrm{COD}) \mathrm{Cl}]_{2}$ and Carreira's (P,olefin) ligand $\left(S_{\mathrm{a}}\right)-\mathbf{L}^{4 \mathrm{~b}}$ (Table 1 , entry 1$)$. In contrast, the reaction with allenylic alcohol rac-2a in combination with $100 \mathrm{~mol}^{2}$ of $\mathrm{Sc}(\mathrm{OTf})_{3}$ as the promoter and $4 \AA$ molecular sieves (MS) as the desiccant under otherwise identical conditions showed complete conversion of the vinyl azide $\mathbf{1 a}$ and led to the formation of 3aa in 44\% isolated yield after $72 \mathrm{~h}$ with $98.5: 1.5$ er (entry 2). More importantly, neither any of the 1,3-dienyl products as shown in Scheme 3 nor the competing allenylation products (4 or 5 ) could be detected. With the increase in the amount of the desiccant, the yield of 3aa was slightly improved (entry 3). However, in both these cases (entries 2-3), a gelatinous material was formed, which points to possible polymerization of the allenylic alcohol. Decreasing the amount of $\mathrm{Sc}(\mathrm{OTf})_{3}$ to $20 \mathrm{~mol} \%$ reduced the extent of polymerization and improved both the yield of 3aa and its er (entry 4). Other Lewis acid promoters were proven to be inferior for this reaction (entries 5-7). The yield of 3aa could be further improved by employing a larger excess of $2 \mathbf{a}$, and the best results were obtained with 2.0 equivalent of 2a. Under these conditions, complete conversion of the vinyl azide 1a took place to furnish 3aa in high yield and with an improved er of 99.5:0.5 (entries 10-11). Further enhancement of enantioselectivity is possible by carrying out the reaction at ambient temperature albeit at the expense of the reaction rate (entry 12).

Table 1. Optimization of Reaction Conditions ${ }^{a}$

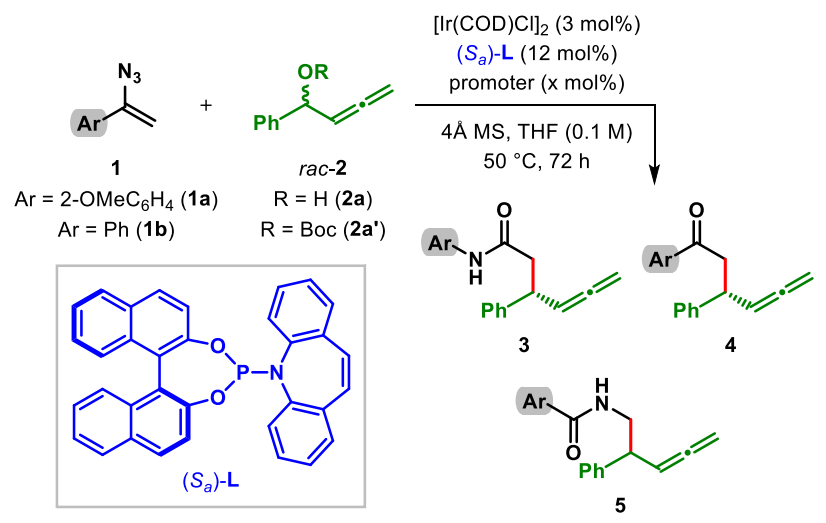

\begin{tabular}{|c|c|c|c|c|c|c|}
\hline & \multirow[b]{2}{*}{1} & \multirow{2}{*}{$\begin{array}{l}\text { promoter } \\
\text { (mol\%) }\end{array}$} & \multicolumn{3}{|c|}{ yield $(\%)^{b}$} & \multirow[b]{2}{*}{$\mathrm{er}^{c}$} \\
\hline & & & 3 & 4 & 5 & \\
\hline $1^{d}$ & 1a & $\mathrm{Sc}(\mathrm{OTf})_{3}(100)$ & $<5$ & 30 & $<5$ & n.d. \\
\hline $2^{e}$ & 1a & $\mathrm{Sc}(\mathrm{OTf})_{3}(100)$ & $\begin{array}{c}45 \\
(44)\end{array}$ & $<5$ & $<5$ & $98.5: 1.5$ \\
\hline 3 & 1a & $\mathrm{Sc}(\mathrm{OTf})_{3}(100)$ & $\begin{array}{c}53 \\
(49)\end{array}$ & $<5$ & $<5$ & $98.5: 1.5$ \\
\hline 4 & $1 a$ & $\mathrm{Sc}(\mathrm{OTf})_{3}(20)$ & 58 & $<5$ & $<5$ & $99.5: 0.5$ \\
\hline 5 & $1 \mathbf{a}$ & $\mathrm{La}(\mathrm{OTf})_{3}(20)$ & 25 & $<5$ & $<5$ & $99: 1$ \\
\hline 6 & $1 \mathrm{a}$ & $\mathrm{Zn}(\mathrm{OTf})_{2}(20)$ & 22 & $<5$ & $<5$ & 99:1 \\
\hline 7 & $1 \mathrm{a}$ & $\mathrm{Fe}(\mathrm{OTf})_{2}(20)$ & 20 & $<5$ & $<5$ & 99:1 \\
\hline $8^{f}$ & $1 a$ & $\mathrm{Sc}(\mathrm{OTf})_{3}(20)$ & 72 & $<5$ & $<5$ & $99: 1$ \\
\hline $9 f$ & $1 \mathrm{a}$ & $\mathrm{Sc}(\mathrm{OTf})_{3}(10)$ & 60 & $<5$ & $<5$ & $99.5: 0.5$ \\
\hline $10^{g}$ & $1 \mathrm{a}$ & $\mathrm{Sc}(\mathrm{OTf})_{3}(20)$ & $\begin{array}{c}95 \\
(92)\end{array}$ & $<5$ & $<5$ & 99.5:0.5 \\
\hline $11^{g, h}$ & $1 a$ & $\mathrm{Sc}(\mathrm{OTf})_{3}(20)$ & (89) & $<5$ & $<5$ & 99.5:0.5 \\
\hline $12^{g, i}$ & $1 \mathrm{a}$ & $\mathrm{Sc}(\mathrm{OTf})_{3}(20)$ & (69) & $<5$ & $<5$ & $>99.5: 0.5$ \\
\hline $13^{g, h, i}$ & $1 b$ & $\mathrm{Sc}(\mathrm{OTf})_{3}(20)$ & $<5$ & $(72)$ & $<5$ & $>99.5: 0.5$ \\
\hline
\end{tabular}

aUnless stated otherwise, the reactions were performed using 1.0 equiv of $\mathbf{1}, 1.2$ equiv of 2 and $100 \mathrm{mg} 4 \AA \mathrm{MS}$ on a $0.1 \mathrm{mmol}$ scale. ${ }^{b} \mathrm{Y}$ ields were determined by ${ }^{1} \mathrm{H}$ NMR spectroscopy with mesitylene as the internal standard. Isolated yields are given in the parentheses. ${ }^{c}$ Enantiomeric ratio (e.r.) of the major product as determined by HPLC analysis using a stationary phase chiral column. ${ }^{d}$ Reaction with $\mathbf{2 a}$ '. ${ }^{e}$ Reaction with $50 \mathrm{mg} 4 \AA$ MS. fReaction with 1.5 equiv of $\mathbf{2 a}$. $g$ Reaction with 2.0 equiv of $\mathbf{2 a}$. ${ }^{h}$ Reaction on a $0.2 \mathrm{mmol}$ scale. ${ }^{i}$ Reaction at $25^{\circ} \mathrm{C} . j$ Reaction without MS. MS $=$ molecular sieves. n.d. $=$ not determined.

We were delighted to note a complete switch of chemoselectivity when the reaction was performed in the absence of the desiccant ( $4 \AA$ MS): Under otherwise identical reaction conditions, $\alpha$-allenylic ketone $\mathbf{4 b a}$ was isolated essentially as a single enantiomer in $72 \%$ yield (Table 1 , entry 13 ). The formation of the $\alpha$-allenylic ketone with the same sense of enantioinduction as that of $\alpha$-allenylic amide (vide infra) clearly indicates the involvement of the same $\mathrm{C}-\mathrm{C}$ bond forming pathway in both these processes and highlights the importance of the desiccant in controlling the endgame (i.e., 
Schmidt rearrangement vs. hydrolysis of iminodiazonium intermediate; see Scheme 2).

The use of a large excess of the racemic allenylic alcohol rac-2a with respect to vinyl azides gives rise to the possibility of a kinetic resolution. However, 2a recovered from incomplete reactions (after $24 \mathrm{~h}$ ) were found to remain racemic although the products 3aa and $\mathbf{4 b a}$ were isolated with the high level of er (Scheme 4). Clearly both the enantiomers of the allenylic alcohol 2a are converted to a single enantiomer of either $\alpha$-allenylic amide (3aa) or $\alpha$-allenylic ketone (4ba) in an enantioconvergent process. Therefore, these reactions proceed via a common carbocationic intermediate and hence represent a dynamic kinetic asymmetric transformation (DyKAT). ${ }^{19}$

\section{Scheme 4. Control Experiments to Eliminate the Possi-} bility of Kinetic Resolution

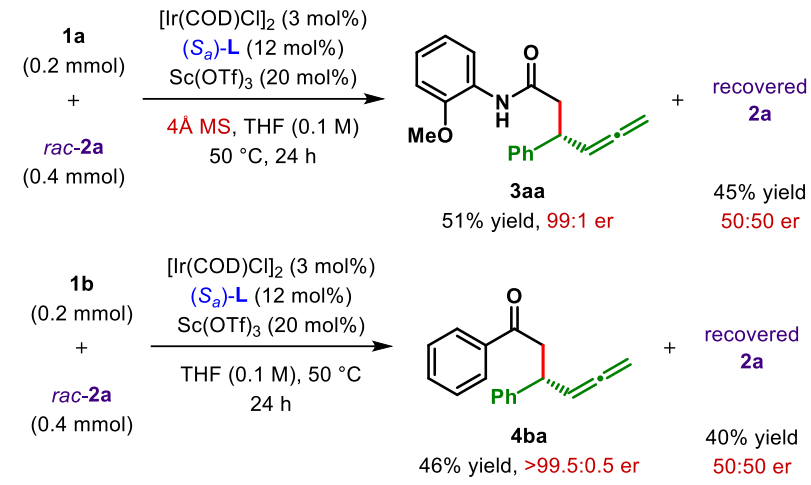

Having optimized the reaction conditions, we set out to showcase the generality of our desiccant-controlled chemodivergent allenylic alkylation of vinyl azide for the enantioselective synthesis of $\alpha$-allenylic amides and ketones. Initially the reaction conditions developed for the synthesis of $\alpha$-allenylic amides (Table 1, entry 11 ) were applied to a range of allenylic alcohols (2) bearing electronically diverse aryl groups (Table 2A). When reacted with 1-(o-methoxyphenyl) vinyl azide 1a, $\alpha$-allenylic amides (3) with excellent level of enantioselectivities were obtained irrespective of the nature and the position of the substituents on the aryl ring. However, the yields of the products appear to be dependent on the electronic nature of the substituents. Moderate yields generally observed for allenylic alcohols having electron-deficient aryl substituent such as 3af supports the involvement of the carbocation intermediate in this reaction. This trend is further corroborated by gradual decrease in the yield while replacing the phenyl group of the allenylic alcohol 2a with monochlorophenyl (2e, 2i) and dichlorophenyl (2k) groups. Ortho-substituent on the aryl ring is detrimental to this allenylic alkylation reaction, presumably due to their inability in stabilizing the carbocation intermediate because of steric crowding. Only 2-methoxyphenyl substituted allenylic alcohol (2j) furnished the product (3aj) in modest yield, albeit with excellent enantioselectivity. The similar level of yield and er was observed with heteroaryl substituted allenylic alcohol $\mathbf{2 m}$.
Table 2. Generality of the Enantioselective Synthesis of $\boldsymbol{\alpha}$-Allenylic Amides ${ }^{a}$

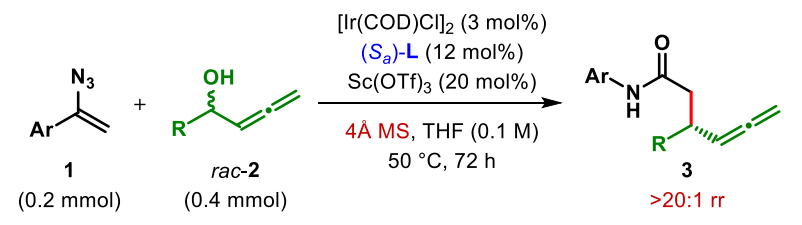

(A) Scope of Allenylic Alcohols

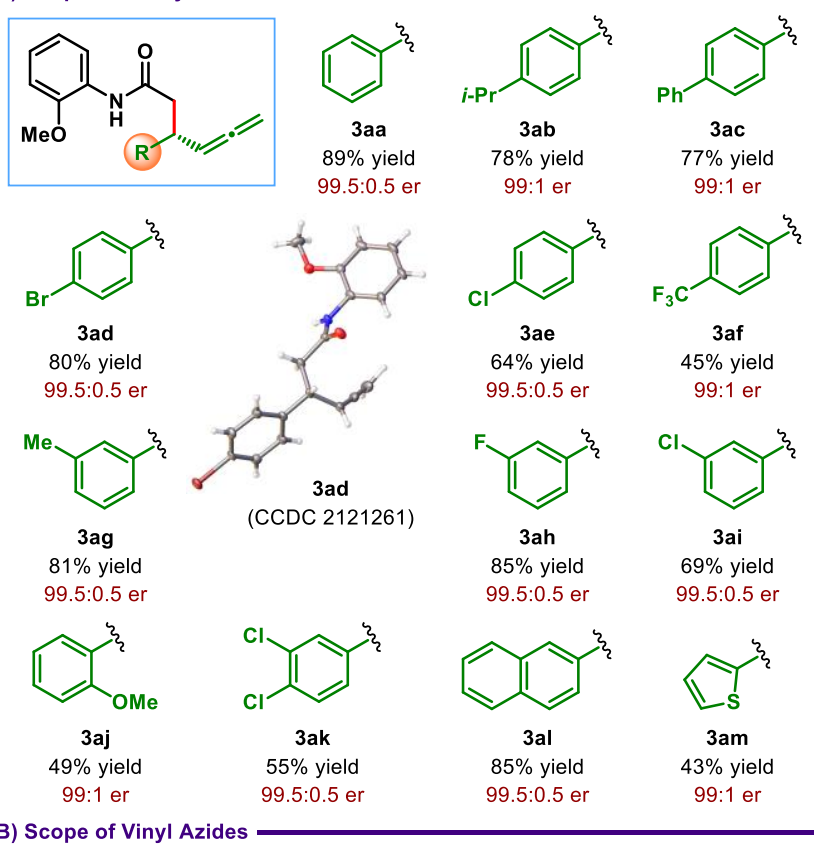

(B) Scope of Vinyl Azides

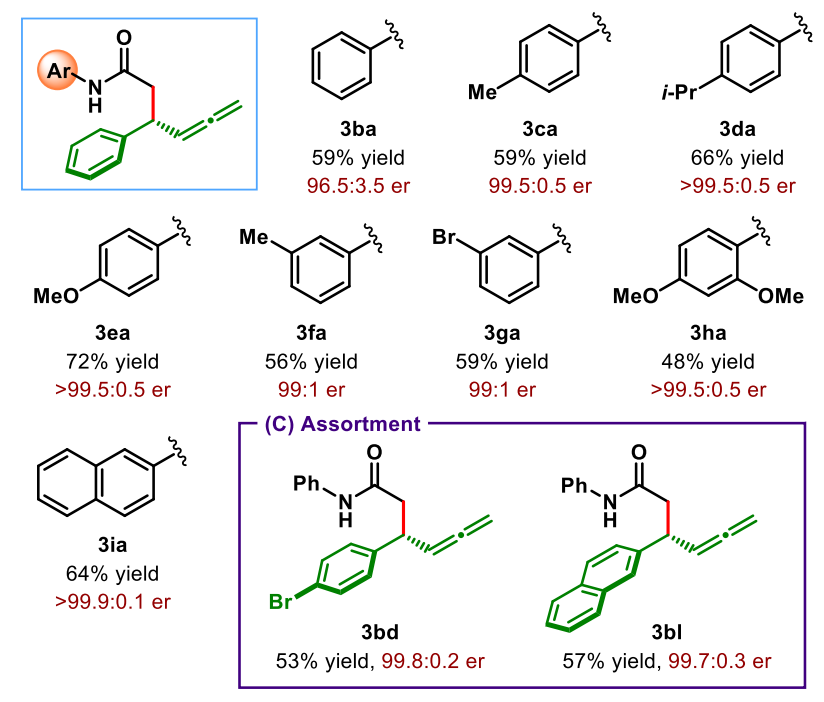

${ }^{a}$ Unless noted otherwise, the reaction conditions indicated above were followed. Yields correspond to the isolated yield after chromatographic purification. Enantiomeric ratio (er) as determined by HPLC analysis using a stationary phase chiral column.

We were pleased to find our optimized reaction conditions to be tolerant to a variety of 1-aryl vinyl azides in addition to the initially assumed 1-(o-methoxyphenyl) vinyl azide 1a (Table 2B). These examples include vinyl azides bearing simple phenyl (1) $\mathbf{1 b}$ and monosubstituted phenyls $(\mathbf{1} \mathbf{c}-\mathbf{g})$ to 2,4-dimethoxyphenyl (1h) and 2-naphthyl groups (1i). In majority of these reactions, the products were formed with 
outstanding enantioselectivity. However, electron deficient 4-trifluoromethylphenyl substituted vinyl azides and sterically congested 1-naphthyl substituted vinyl azides failed to deliver any product under our standard conditions. The examples shown in Table 2C illustrate the modular nature of this fragment coupling strategy, which could be used for synthesizing a library $\alpha$-allenylic amides.

Table 3. Generality of the Enantioselective Synthesis of $\alpha$-Allenylic Ketones ${ }^{a}$

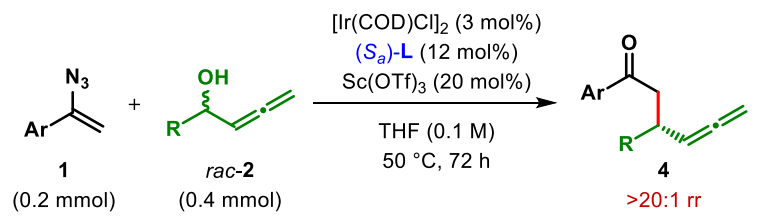

(A) Scope of Allenylic Alcohols
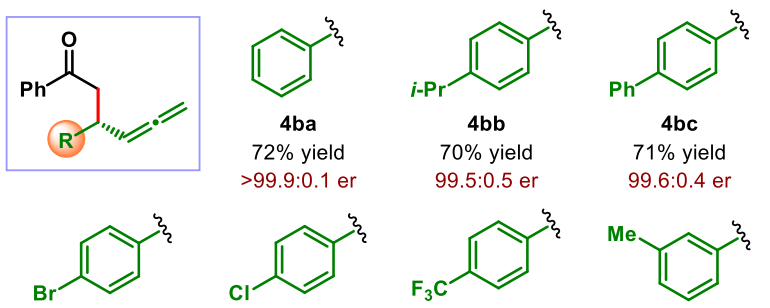

4 be

$84 \%$ yield 99.6:0.4 er

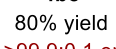

$4 \mathrm{bf}$

$70 \%$ yield

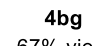

$99.7: 0.3 \mathrm{er}$
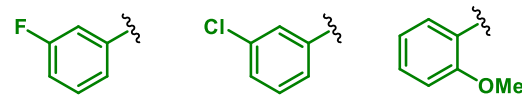

4bh

$79 \%$ yield

$>99.9: 0.1$ er

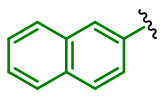

4bl

$67 \%$ yield

99.7:0.3 er

4bi

$76 \%$ yield

$>99.9: 0.1$ er

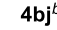

$57 \%$ yield

99.5:0.5 er $>99.9: 0.1$ er

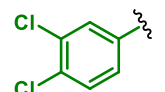

4 bk

$82 \%$ yield

$>99.9: 0.1$ er

(B) Scope of Vinyl Azides
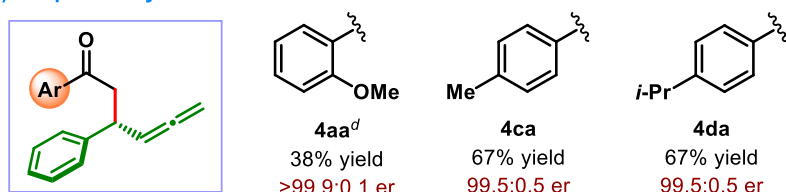

$38 \%$ yield

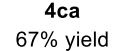

$67 \%$ yield

$67 \%$ yield

99.5:0.5 er
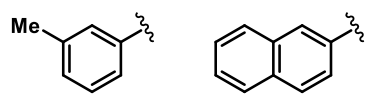

$4 \mathrm{fa}$

$70 \%$ yield

99.5:0.5 er

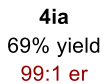

${ }^{a}$ Unless noted otherwise, the reaction conditions indicated above were followed. Yields correspond to the isolated yield after chromatographic purification. Enantiomeric ratio (er) as determined by HPLC analysis using a stationary phase chiral column. ${ }^{b}$ Reaction at 25 ${ }^{\circ} \mathrm{C}$ for $60 \mathrm{~h}$. ${ }^{c}$ Reaction at $25^{\circ} \mathrm{C}$ for $24 \mathrm{~h}$ followed by $50{ }^{\circ} \mathrm{C}$ for $48 \mathrm{~h}$. ${ }^{d}$ Reaction with $5 \mathrm{~mol} \% \mathrm{Sc}(\mathrm{OTf})_{3}$ at $25^{\circ} \mathrm{C}$ for $24 \mathrm{~h}$.

In all these cases, the products were formed as a single regioisomer (allene vs. 1,3-diene). It must also be noted that neither $\alpha$-allenylic acetophenone (4) nor $N$-homoallenylic benzamide (5) derivatives could be detected in most of these reactions. Only in the case of phenyl vinyl azide $\mathbf{1 b}$, small amounts of $\alpha$-allenylic acetophenones were formed. ${ }^{20}$

The structure of $\mathbf{3 a d}$ in solid state obtained through X-ray diffraction analysis established its absolute configuration to be $(R)$ (CCDC 2121261, Table 2A). The configurations of the other $\alpha$-allenylic amides were tentatively assigned to be the same by analogy.

After demonstrating the substrate generality of the route leading to the $\alpha$ allenylic amides, we turned out attention to $\alpha$ allenylic ketones. Under the reaction conditions utilized for the synthesis of $\alpha$-allenylic amides, minus $4 \AA$ molecular sieves (see Table 1, entry 13), the fragment-coupling reaction between vinyl azides (1) and allenylic alcohols (2) took place efficiently to furnish a range of $\alpha$-allenylic ketones (4) in moderate to good yields with superb enantioselectivity (Table 3). Although 1-phenyl vinyl azide (1b) was initially chosen to examine the scope of allenylic alcohols 2 (Table $3 \mathrm{~A}$ ), we were excited to find that the same substrate combinations used for the synthesis of $\alpha$-allenylic amides now resulted in $\alpha$-allenylic ketones with similar yield and equally high enantioselectivity (Table 3B). Once again, no regioisomeric 1,3-diene or the corresponding $\alpha$-allenylic amide (3) were found to form in any of these reactions. Therefore, this chemodivergency appears to be devoid of steric or electronic bias and controlled primarily by the presence or the absence of the desiccant.

The conversion of the $\alpha$ allenylic ketone $\mathbf{4 b l}$ to the corresponding oxime 6 followed by Beckmann rearrangement with $p$-TsOH-ZnCl ${ }_{2}^{21}$ led to $\alpha$-allenylic amide $\mathbf{3 b l}$ (Scheme $5)$. The absolute configuration of $\mathbf{3 b l}$ obtained in this reaction is found to be the same as that of $\mathbf{3} \mathbf{b l}$ formed under our standard conditions (Table 2) by comparing their specific rotations. These data clearly indicate that the enantiodetermining steps of these chemodivergent allenylic alkylation reactions are identical and precede either the Schmidt rearrangement or the hydrolysis of the iminodiazonium intermediate (see Scheme 2). Therefore, it is likely that the nucleophilic addition of vinyl azide to the allenylic carbocation is the enantiodetermining step in both these reactions.

\section{Scheme 5. Determination of Absolute Configuration of $\alpha$-Allenylic Ketone 4bl}

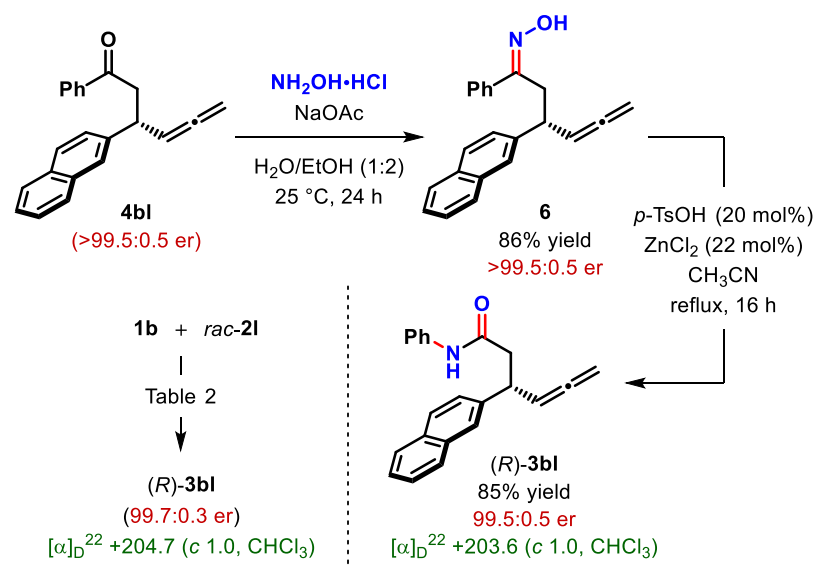

The scalability of our protocols is exhibited by conducting a few of these allenylic alkylations reactions on a $1.0 \mathrm{mmol}$ 
scale (Scheme 6A). In all these cases, the products were obtained in equally high yields with similar level of enantioselectivities as seen for smaller scale reactions (Tables 2-3).

Scheme 6. (A) One mmol Scale Synthesis of $\alpha$-Allenylic Amides and Ketones. (B) Synthetic Elaboration of $\alpha$-Allenylic Amide and (C) Ketones
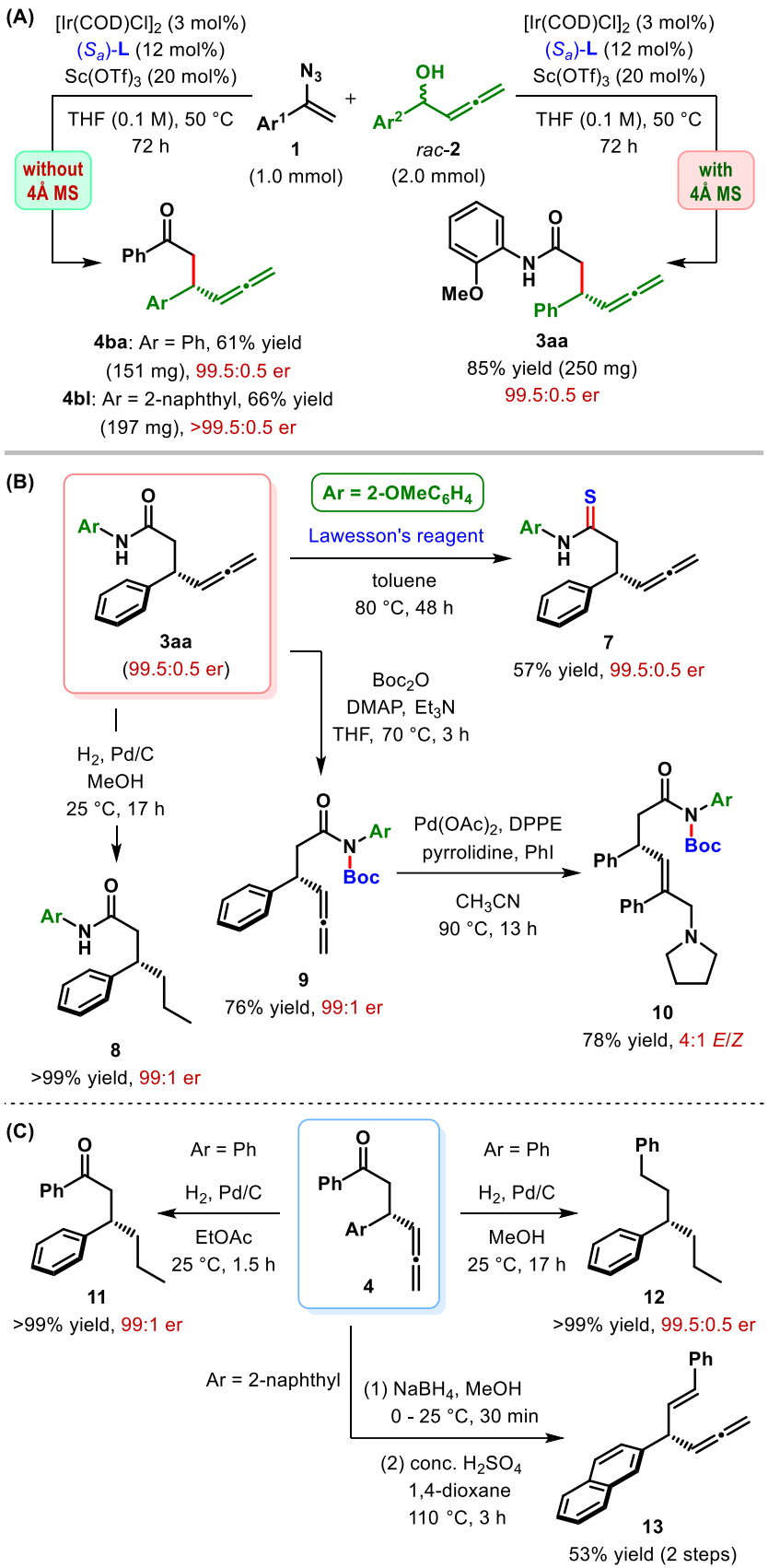

The presence of the synthetically versatile allene and carbonyls in the products makes them amenable to a wide variety of functional group elaborations. A few such synthetic diversifications are demonstrated in Scheme 6. For example, heating with Lawesson's reagent in toluene turned the $\alpha$-allenylic amide 3aa into the corresponding thioamide $\mathbf{7}$ (Scheme 6B). Catalytic hydrogenation of 3aa led to the complete reduction of the allene functionality and furnished
$\mathrm{N}$-aryl-3-phenylhexanamide $\mathbf{8}$ in quantitative yield. Although the Pd-catalyzed aminoarylation of allene ${ }^{22}$ directly on 3aa remained unsuccessful, the reaction proceeded efficiently on the terminal double bond of allene of the corresponding $N$-Boc-protected $\alpha$-allenylic amide 9 . The resulting aminoarylation product $\mathbf{1 0}$ was obtained in good yield but as a 4:1 mixture of diastereomers.

Selective reduction of the functionalities in $\alpha$-allenylic ketones is possible under controlled hydrogenation conditions. While the selective hydrogenation of the allene functionality in $4 \mathrm{ba}$ can be achieved in EtOAc within $1.5 \mathrm{~h}$, prolonged exposure to hydrogen under $\mathrm{Pd} / \mathrm{C}$ in $\mathrm{MeOH}$ met with global reduction of $\mathbf{4 b a}$ (Scheme $6 \mathrm{C}$ ). In both these cases, the products $\mathbf{1 1}$ and $\mathbf{1 2}$ were formed in quantitative yield. Even though the ketone $\mathbf{1 1}$ can be viewed as the conjugate addition product of an enone, direct enantioselective synthesis of the chiral hydrocarbon $\mathbf{1 2}$ may not be straightforward.

Skipped polyenes is an important functionality whose enantioselective synthesis is rather challenging. ${ }^{23} \mathrm{We}$ envisioned an easy access to such skipped polyenes starting from $\alpha$ allenylic ketones. As exemplified with $\mathbf{4 b l}$, reduction of ketone to the corresponding alcohol followed by dehydration under acidic conditions delivered the skipped eneallene $\mathbf{1 3}$ in decent yield over two steps.

\section{CONCLUSION}

In conclusion, we have discovered the first enantioselective syntheses of $\alpha$-allenylic amides and ketones. In these chemodivergent allenylic alkylation reactions, cooperatively catalyzed by an $\operatorname{Ir}(\mathrm{I}) /($ phosphoramidite,olefin) complex and $\mathrm{Sc}(\mathrm{OTf})_{3}$, vinyl azides act as the surrogate for both amide enolates and ketone enolates. Under otherwise identical reaction conditions using racemic allenylic alcohol as the source of allenylic unit, the desiccant ( $4 \AA$ MS) plays a crucial role in controlling the chemodivergency of these fragment-coupling dynamic kinetic asymmetric transformations (DyKATs). While the presence of the desiccant led to $\alpha$-allenylic amides, its absence resulted in $\alpha$ allenylic ketones from the same set of substrates. The formation of both these products, bearing a $\beta$-stereogenic center, with the same absolute configuration and very similar level of enantiomeric ratios clearly point to the mechanistic commonality of these two processes. Importantly, both $\alpha$ allenylic amides and ketones are obtained with exquisite regioselectivity and in most cases with outstanding enantioselectivity for a range of vinyl azides and allenylic alcohols. To the best of our knowledge, this is the first-time vinyl azide is used as the ketone enolate surrogate in an enantioselective transformation. In this era, when the economy of synthesis and the waste management are of prime concern, such a clean chemodivergent catalytic process should instigate further applications of vinyl azides in fragment-coupling processes.

\section{ASSOCIATED CONTENT}

\section{Supporting Information}

The Supporting Information is available free of charge via the Internet at http://pubs.acs.org. 
Experimental details and characterization data NMR spectra and HPLC chromatograms

\section{AUTHOR INFORMATION}

\section{Corresponding Author}

*E-mail: sm@iisc.ac.in

\section{Author Contributions}

The manuscript was written through contributions of all authors.

\section{ORCID}

Aditya Chakrabarty: 0000-0003-3470-069X

Santanu Mukherjee: 0000-0001-9651-6228

\section{Notes}

The authors declare no competing financial interest.

\section{ACKNOWLEDGMENT}

We gratefully acknowledge the financial support from the Science and Engineering Research Board (SERB) [Grant No. CRG/2020/000176] and the Council of Scientific and Industrial Research (CSIR) [Grant no. 02(0385)/19/EMR-II]. A.C. thanks the Ministry of Education, Government of India for his doctoral fellowship through the Prime Minister's Research Fellowship (PMRF) scheme. High resolution mass spectra (HR-MS) were recorded on an equipment procured under the Department of Science and Technology (DST)-FIST grant [Grant No. SR/FST/CS II-040/2015]. We thank Ms. Krishna Kaushik (Solid State and Structural Chemistry Unit, IISc, Bangalore) for her help with the X-ray diffraction analysis. We wish to thank Mr. Suman Ghosh for helpful discussion.

\section{REFERENCES}

(1) (a) Tomanik, M.; Hsu, I. T.; Herzon, S. B. Fragment Coupling Reactions in Total Synthesis That Form Carbon-Carbon Bonds via Carbanionic or Free Radical Intermediates. Angew. Chem., Int. Ed. 2021, 60, 1116-1150. (b) Pitre, S. P.; Weires, N. A.; Overman, L. E. Forging $\mathrm{C}\left(\mathrm{sp}^{3}\right)-\mathrm{C}\left(\mathrm{sp}^{3}\right)$ Bonds with Carbon-Centered Radicals in the Synthesis of Complex Molecules. J. Am. Chem. Soc. 2019, 141, 28002813. (c) Inoue, M. Evolution of Radical-Based Convergent Strategies for Total Syntheses of Densely Oxygenated Natural Products. Acc. Chem. Res. 2017, 50, 460-464. (d) Jamison, C. R.; Overman, L. E. Fragment Coupling with Tertiary Radicals Generated by VisibleLight Photocatalysis. Acc. Chem. Res. 2016, 49, 1578-1586.

(2) For selected reviews, see: (a) Zhuo, C.-X.; Zheng, C.; You, S.-L. Transition-Metal-Catalyzed Asymmetric Allylic Dearomatization Reactions. Acc. Chem. Res. 2014, 47, 2558-2573. (b) Hartwig, J. F. Allylic Substitution. In Organotransition Metal Chemistry; University Science Books: Sausalito, CA, 2010; Chapter 20, pp 967-1014. (c) Lu, Z.; Ma, S. Metal-Catalyzed Enantioselective Allylation in Asymmetric Synthesis. Angew. Chem., Int. Ed. 2008, 47, 258-297. (d) Trost, B. M. Asymmetric Allylic Alkylation, an Enabling Methodology. J. Org. Chem. 2004, 69, 5813-5837. (e) Trost, B. M.; Van Vranken, D. L. Asymmetric Transition Metal-Catalyzed Allylic Alkylations. Chem. Rev. 1996, 96, 395-422.

(3) For reviews on Pd-catalyzed AAS reactions, see: (a) Trost, B. M.; Schultz, J. E. Palladium-Catalyzed Asymmetric Allylic Alkylation Strategies for the Synthesis of Acyclic Tetrasubstituted Stereocenters. Synthesis 2019, 51, 1-30. (b) Kammerer, C.; Prestat, G.; Madec, D.; Poli, G. Synthesis of $\gamma$-Lactams and $\gamma$-Lactones via Intramolecular Pd-Catalyzed Allylic Alkylations. Acc. Chem. Res. 2014, 47, 34393447. (c) Trost, B. M.; Crawley, M. L. Asymmetric Transition-MetalCatalyzed Allylic Alkylations: Applications in Total Synthesis.
Chem. Rev. 2003, 103, 2921-2943. (d) Trost, B. M. Pd Asymmetric Allylic Alkylation (AAA). A Powerful Synthetic Tool. Chem. Pharm. Bull. 2002, 50, 1-14.

(4) For reviews on Ir-catalyzed AAS reactions, see: (a) Cheng, Q.; Tu, H.-F.; Zheng, C.; Qu, J.-P.; Helmchen, G.; You, S.-L. Iridium-Catalyzed Asymmetric Allylic Substitution Reactions. Chem. Rev. 2019, 119, 1855-1969. (b) Rössler, S. L.; Petrone, D. A.; Carreira, E. M. Iridium-Catalyzed Asymmetric Synthesis of Functionally Rich Molecules Enabled by (Phosphoramidite,Olefin) Ligands. Acc. Chem. Res. 2019, 52, 2657-2672. (c) Shockley, S. E.; Hethcox, J. C.; Stoltz, B. M. Intermolecular Stereoselective Iridium-Catalyzed Allylic Alkylation: An Evolutionary Account. Synlett 2018, 29, 2481-2492. (d) Qu, J.; Helmchen, G. Applications of Iridium-Catalyzed Asymmetric Allylic Substitution Reactions in Target-Oriented Synthesis. Acc. Chem. Res. 2017, 50, 2539-2555. (e) Hethcox, J. C.; Shockley, S. E.; Stoltz, B. M. Iridium-Catalyzed Diastereo-, Enantio-, and Regioselective Allylic Alkylation with Prochiral Enolates. ACS Catal. 2016, 6, 6207-6213. (f) Tosatti, P.; Nelson, A.; Marsden, S. P. Recent advances and applications of iridium-catalysed asymmetric allylic substitution. Org. Biomol. Chem. 2012, 10, 3147-3163. (g) Hartwig, J. F.; Stanley, L. M. Mechanistically Driven Development of Iridium Catalysts for Asymmetric Allylic Substitution. Acc. Chem. Res. 2010, 43, 1461-1475. (h) Helmchen, G.; Dahnz, A.; Dübon, P.; Schelwies, M.; Weihofen, R. Iridium-Catalysed Asymmetric Allylic Substitutions. Chem. Commun. 2007, 675-691.

(5) For selected reviews, see: (a) Alonso, J. M.; Almendros, P. Deciphering the Chameleonic Chemistry of Allenols: Breaking the Taboo of a Onetime Esoteric Functionality. Chem. Rev. 2021, 121, 4193-4252. (b) Gellrich, U. Reactions of Allenes with strong Borane-Based Lewis Acids. Eur. J. Org. Chem. 2021, 4707-4714. (c) Lechel, T.; Pfrengle, F.; Reissig, H.-U.; Zimmer, R. Three Carbons for Complexity! Recent Developments of Palladium-Catalyzed Reactions of Allenes. ChemCatChem 2013, 5, 2100-2130. (d) Ma, S. Some Typical Advances in the Synthetic Applications of Allenes. Chem. Rev. 2005, 105, 2829-2871. (e) Zimmer, R.; Dinesh, C. U.; Nandanan, E.; Khan, F. A. Palladium-Catalyzed Reactions of Allenes. Chem. Rev. 2000, 100, 3067-3125. (f) Taylor, D. R. The Chemistry of Allenes. Chem. Rev. 1967, 67, 317-359.

(6) (a) Trost, B. M.; Tour, J. M. Synthesis of 4-(Dimethylphenylsilyl)buta-2,3-dien-1-ol and its Use in Alkylation. J. Org. Chem. 1989, 54, 484-486. (b) Cazes, B.; Djahanbini, D.; Goré, J.; Genêt, J.-P.; Gaudin, J.-M. Palladium-Catalyzed Synthesis of $\gamma$-Allenic $\alpha$-Amino Acids. Synthesis 1988, 983-985. (c) Djahanbini, D.; Cazes, B.; Gore, J. Organopalladiques Issus des Esters D'alcools $\alpha$-Alleniques : Reactions Avec les Anions Delocalises. Tetrahedron 1987, 43, 34413452. (d) Djahanbini, D.; Cazes, B.; Gore, J. Reactive D'esters $\alpha$ Alleniques. Synthese Regiospecifique de Diesters $\gamma$-Alleniques et de Dienes-1,3. Tetrahedron Lett. 1984, 25, 203-206.

(7) (a) Song, S.; Zhou, J.; Fu, C.; Ma, S. Catalytic Enantioselective Construction of Axial Chirality in 1,3-Disubstituted Allenes. Nature Communications 2019, 10:507. (b) Wan, B.; Ma, S. Enantioselective Decarboxylative Amination: Synthesis of Axially Chiral Allenyl Amines. Angew. Chem., Int. Ed. 2013, 52, 441-445. (c) Nemoto, T.; Kanematsu, M.; Tamura, S.; Hamada, Y. Palladium-Catalyzed Asymmetric Allylic Alkylation of 2,3-Allenyl Acetates Using a Chiral Diaminophosphine Oxide. Adv. Synth. Catal. 2009, 351, 1773-1778. (d) Imada, Y.; Nishida, M.; Naota, T. Sequential Asymmetric Homoallenylation of Primary Amines with a Palladium Catalyst. Tetrahedron Lett. 2008, 49, 4915-4917. (e) Trost, B. M.; Fandrick, D. R.; Dinh, D. C. Dynamic Kinetic Asymmetric Allylic Alkylations of Allenes. J. Am. Chem. Soc. 2005, 127, 14186-14187. (f) Imada, Y.; Nishida, M.; Kutsuwa, K.; Murahashi, S.-I.; Naota, T. Palladium-Catalyzed Asymmetric Amination and Imidation of 2,3-Allenyl Phosphates. Org. Lett. 2005, 7, 5837-5839. (g) Imada, Y.; Ueno, K.; Kutsuwa, K.; Murahashi, S.-I. Palladium-Catalyzed Asymmetric Alkylation of 2,3-Alkadienyl Phosphates. Synthesis of Optically Active 2-(2,3-Alkadienyl)malonates. Chem. Lett. 2002, 31, 140-141.

(8) (a) Xiao, J.; Xu, H.; Huo, X.; Zhang, W.; Ma, S. One Stone Two Birds-Enantioselective Bimetallic Catalysis for $\alpha$-Amino Acid 
Derivatives with an Allene Unit. Chin. J. Chem. 2021, 39, 1958-1964. (b) Liu, H.-C.; Hu, Y.-Z.; Wang, Z.-F.; Tao, H.-Y.; Wang, C.-J. Synergistic $\mathrm{Cu} / \mathrm{Pd}$-Catalyzed Asymmetric Allenylic Alkylation of Azomethine Ylides for the Construction of $\alpha$-Allene-Substituted Nonproteinogenic $\alpha$-Amino Acids. Chem.-Eur. J. 2019, 25, 8681-8685. (c) Li, Q.; Fu, C.; Ma, S. Palladium-Catalyzed Asymmetric Amination of Allenyl Phosphates: Enantioselective Synthesis of Allenes with an Additional Unsaturated Unit. Angew. Chem., Int. Ed. 2014, 53, 65116514. (d) Li, Q.; Fu, C.; Ma, S. Catalytic Asymmetric Allenylation of Malonates with the Generation of Central Chirality. Angew. Chem., Int. Ed. 2012, 51, 11783-11786.

(9) (a) Zhang, J.; Huo, X.; Xiao, J.; Zhao, L.; Ma, S.; Zhang, W. Enantioand Diastereodivergent Construction of 1,3-Nonadjacent Stereocenters Bearing Axial and Central Chirality through Synergistic Pd/Cu Catalysis. J. Am. Chem. Soc. 2021, 143, 12622-12632. (b) Dai, J.; Duan, X.; Zhou, J.; Fu, C.; Ma, S. Catalytic Enantioselective Simultaneous Control of Axial Chirality and Central Chirality in Allenes. Chin. J. Chem. 2018, 36, 387-391. Also see: 8b.

(10) Kezuka, S.; Kanemoto, K.; Takeuchi, R. Iridium Complex-Catalyzed Method for the Construction of a Quaternary Carbon Center $\alpha$ to Allene. Tetrahedron Lett. 2004, 45, 6403-6406.

(11) Petrone, D. A.; Isomura, M.; Franzoni, I.; Rössler, S. L.; Carreira, E. M. Allenylic Carbonates in Enantioselective Iridium-Catalyzed Alkylations. J. Am. Chem. Soc. 2018, 140, 4697-4704.

(12) (a) Isomura, M.; Petrone, D. A.; Carreira, E. M. Construction of Vicinal Quaternary Centers via Iridium-Catalyzed Asymmetric Allenylic Alkylation of Racemic Tertiary Alcohols. J. Am. Chem. Soc 2021, 143, 3323-3329. (b) Glatz, F.; Petrone, D. A.; Carreira, E. M. Ir-Catalyzed Enantioconvergent Synthesis of Diversely Protected Allenylic Amines Employing Ammonia Surrogates. Angew. Chem., Int. Ed. 2020, 59, 16404-16408. (c) Isomura, M.; Petrone, D. A.; Carreira, E. M. Coordination-Induced Stereocontrol over Carbocations: Asymmetric Reductive Deoxygenation of Racemic Tertiary Alcohols. J. Am. Chem. Soc. 2019, 141, 4738-4748.

(13) (a) Lu, T.; Lu, Z.; Ma, Z.-X.; Zhang, Y.; Hsung, R. P. Allenamides: A Powerful and Versatile Building Block in Organic Synthesis. Chem. Rev. 2013, 113, 4862-4904. (b) Yu, S.; Ma, S. Allenes in Catalytic Asymmetric Synthesis and Natural Product Syntheses. Angew. Chem., Int. Ed. 2012, 51, 3074-3112. (c) Hoffmann-Röder, A.; Krause, N. Synthesis and Properties of Allenic Natural Products and Pharmaceuticals. Angew. Chem., Int. Ed. 2004, 43, 1196-1216.

(14) Bordwell, F. G. Equilibrium Acidities in Dimethyl Sulfoxide Solution. Acc. Chem. Res. 1988, 21, 456-463.

(15) (a) Chakrabarty, A.; Mukherjee, S. Iridium-Catalyzed Enantioselective $\alpha$-Allylic Alkylation of Amides Using Vinyl Azide as Amide Enolate Surrogate. Org. Lett. 2020, 22, 7752-7756. (b) Han, M.; Yang, M.; Wu, R.; Li, Y.; Jia, T.; Gao, Y.; Ni, H.-L.; Hu, P.; Wang, B.-Q.; Cao, P. Highly Enantioselective Iridium-Catalyzed Coupling Reaction of Vinyl Azides and Racemic Allylic Carbonates. J. Am. Chem. Soc. 2020, 142, 13398-13405. (c) Sempere, Y.; Alfke, J. L.; Rössler, S. L.; Carreira, E. M. Morpholine Ketene Aminal as Amide Enolate Surrogate in Iridium-Catalyzed Asymmetric Allylic Alkylation. Angew. Chem., Int. Ed. 2019, 58, 9537-9541.

(16) (a) Nakanishi, T.; Kikuchi, J.; Kaga, A.; Chiba, S.; Terada, M. OnePot Synthesis of Enantioenriched $\beta$-Amino Secondary Amides via an Enantioselective [4+2] Cycloaddition Reaction of Vinyl Azides with N-Acyl Imines Catalyzed by a Chiral Brønsted Acid Chem.-Eur. J. 2020, 26, 8230-8234. (b) Hayashi, H.; Kaga, A.; Chiba, S. Application of Vinyl Azides in Chemical Synthesis: A Recent Update. J. Org. Chem. 2017, 82, 11981-11989. (c) Zhang, F.-L.; Zhu, X.; Chiba, S.
$\mathrm{Tf}_{2} \mathrm{NH}$-Catalyzed Amide Synthesis from Vinyl Azides and Alcohols. Org. Lett. 2015, 17, 3138-3141. (d) Zhang, F.-L.; Wang, Y.-F.; Lonca, G. H.; Zhu, X.; Chiba, S. Amide Synthesis by Nucleophilic Attack of Vinyl Azides. Angew. Chem., Int. Ed. 2014, 53, 4390-4394. Also see: (e) Das, D. K.; Kannaujiya, V. K.; Sadhu, M. M.; Ray, S. K.; Singh, V. K. $\mathrm{BF}_{3} \cdot \mathrm{OEt}_{2}$-Catalyzed Vinyl Azide Addition to in Situ Generated NAcyl Iminium Salts: Synthesis of 3-0xoisoindoline-1-acetamides. J. Org. Chem. 2019, 84, 15865-15876. (f) Rasool, F.; Ahmed, A.; Hussain, N.; Yousuf, S. K.; Mukherjee, D. One-Pot Regioselective and Stereoselective Synthesis of C-Glycosyl Amides from Glycals Using Vinyl Azides as Glycosyl Acceptors. Org. Lett. 2018, 20, 4036-4039. (g) Lin, C.; Shen, Y.; Huang, B.; Liu, Y.; Cui, S. Synthesis of Amides and Nitriles from Vinyl Azides and p-Quinone Methides. J. Org. Chem. 2017, 82, 3950-3956. (h) Zhang, Z.; Kumar, R. K.; Li, G.; Wu, D.; Bi, X. Synthesis of 4-Ynamides and Cyclization by the Vilsmeier Reagent to Dihydrofuran-2(3H)-ones. Org. Lett. 2015, 17, 61906193. For an early report, see: (i) Hassner, A.; Ferdinandi, E. S.; Isbister, R. J. Hydrolysis of Vinyl Azides. A Comparison with the Schmidt Reaction. J. Am. Chem. Soc. 1970, 92, 1672-1675.

(17) For a non-enantioselective approach to $\alpha$-allenylic ketones, see: Zhu, T.; Ma, S. 3,4-Alkadienyl Ketones via the Palladium-Catalyzed Decarboxylative Allenylation of 3-0xocarboxylic Acids. Chem. Commun. 2017, 53, 6037-6040.

(18) For selected examples, see: (a) Mao, M.; Zhang, L.; Chen, Y.-Z.; Zhu, J.; Wu, L. Palladium-Catalyzed Coupling of Allenylphosphine Oxides with N-Tosylhydrazones toward Phosphinyl [3]Dendralenes. ACS Catal. 2017, 7, 181-185. (b) Wang, H.; Beiring, B.; Yu, D.-G.; Collins, K. D.; Glorius, F. [3]Dendralene Synthesis: Rhodium(III)-Catalyzed Alkenyl C-H Activation and Coupling Reaction with Allenyl Carbinol Carbonate. Angew. Chem., Int. Ed. 2013, 52, 12430-12434. (c) Moriya, T.; Furuuchi, T.; Miyaura, N.; Suzuki, A. A New Facile Synthesis of 2-Substituted 1,3-Butadiene Derivatives via Palladium-Catalyzed Cross-Coupling Reaction of 2,3-Alkadienyl Carbonates with Organoboron Compounds. Tetrahedron 1994, 50 7961-7968. (d) Ni, Z.; Padwa, A. Palladium Catalyzed Cross Coupling Reaction of $\alpha$-Allenyl Acetates under Nonbasic Conditions. Synlett 1992, 869-870. (e) Djahanbini, D.; Cazes, B.; Gore, J. Synthese Stereoselective de Dienes Conjugues a Partir D'alcools $\alpha$-Alleniques. Tetrahedron 1984, 40, 3645-3655.

(19) Steinreiber, J.; Faber, K.; Griengl, H. De-racemization of Enantiomers versus De-epimerization of Diastereomers - Classification of Dynamic Kinetic Asymmetric Transformations (DYKAT). Chem.Eur. J. 2008, 14, 8060-8072.

(20) For details, see the Supporting Information.

(21) Xiao, L.; Xia, C.; Chen, J. $p$-Toluenesulfonic Acid Mediated Zinc Chloride: Highly Effective Catalyst for the Beckmann Rearrangement. Tetrahedron Lett. 2007, 48, 7218-7221.

(22) Shimizu, I.; Tsuji, J. Palladium-Catalyzed Synthesis of 2,3-Disubstituted Allylamines by Regioselective Aminophenylation or Aminoalkenylation of 1,2-Dienes. Chem. Lett. 1984, 13, 233-236.

(23) (a) Petruncio, G.; Shellnutt, Z.; Elahi-Mohassel, S.; Alishetty, S. Paige, M. Skipped dienes in natural product synthesis. Nat. Prod. Rep., DOI: 10.1039/d1np00012h. (b) Sato, T.; Suto, T.; Nagashima, Y.; Mukai, S.; Chida, N. Total Synthesis of Skipped Diene Natural Products. Asian J. Org. Chem. 2021, 10, 2486-2502. 


\section{Table of Contents artwork}

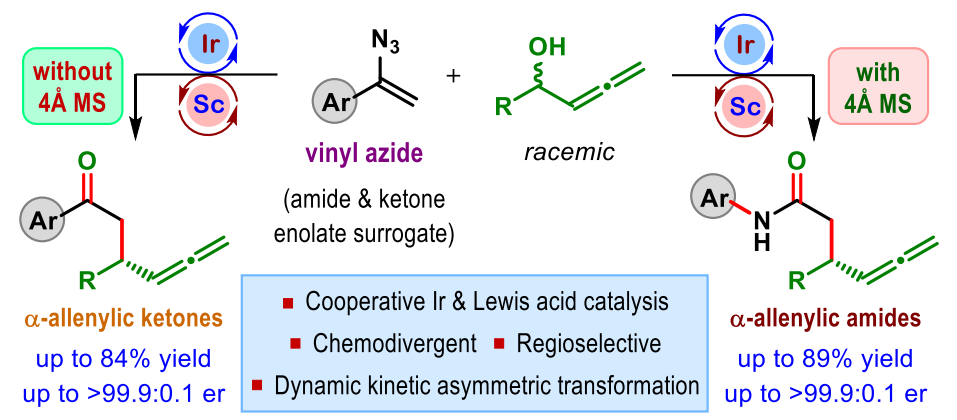

